\title{
N $71-26430$
}

\section{NASA TECHNICAL MEMORANDUM}

\author{
NASA TM X-64601
}

\section{ANALYSIS OF A CONTROL SYSTEM CONTA INING TWO NONLINEARITIES}

By S. M. Seltzer

Astrionics Laboratory

NASA

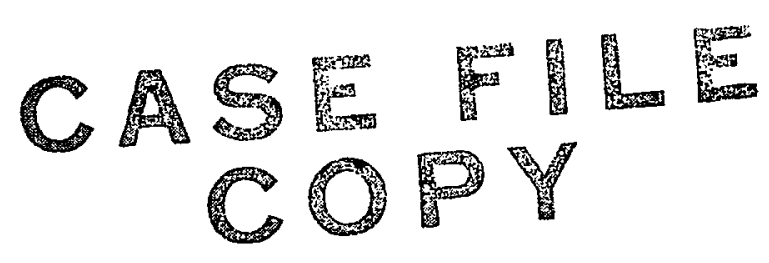

George C. Marshall Space Flight Center Marshall Space Flight Center, Alabama 
TECHNICAL REPORT ST ANDARD TITLE PAGE

\begin{tabular}{|c|c|c|c|}
\hline $\begin{array}{l}\text { 1. REPORT NO. } \\
\text { NASA TM X-64601 }\end{array}$ & 2. GOVERNMENT ACCESSION NO: & \multicolumn{2}{|c|}{ 3. RECIPIENT'S CATAL.OG NO. } \\
\hline \multirow{2}{*}{\multicolumn{2}{|c|}{$\begin{array}{l}\text { 4. TITLE AND SUBTITLE } \\
\text { Analysis of a Control System } \\
\text { Containing Two Nonlinearities }\end{array}$}} & \multicolumn{2}{|c|}{$\begin{array}{l}\text { 5. REPORT DATE } \\
\text { April 30, } 1971\end{array}$} \\
\hline & & \multicolumn{2}{|c|}{ 6. PERFORMING ORGANIZATION CODE } \\
\hline \multicolumn{2}{|l|}{$\begin{array}{l}\text { 7. AUTHOR (S) } \\
\text { S. M. Seltzer }\end{array}$} & \multicolumn{2}{|c|}{ 8. PERFORMING ORGANIZATION REPORT } \\
\hline \multirow{2}{*}{\multicolumn{2}{|c|}{$\begin{array}{l}\text { PERFORMING ORGANIZATION NAME AND ADORESS } \\
\text { George C. Marshall Space Flight Center } \\
\text { Marshall Space Flight Center, Alabama } 35812\end{array}$}} & \multicolumn{2}{|l|}{ 10. WORK UNIT NO. } \\
\hline & & \multicolumn{2}{|c|}{ 11. CONTRACT OR GRANT NO. } \\
\hline \multirow{2}{*}{\multicolumn{2}{|c|}{$\begin{array}{l}\text { 12. SPONSORING AGENCY NAME AND ADDRESS } \\
\text { National Aeronautics and Space Administration } \\
\text { Washington, D. C, } 20546\end{array}$}} & \multicolumn{2}{|c|}{ Technical Memorandum } \\
\hline & & \multicolumn{2}{|c|}{ 14. SPONSORING AGENCY CODE } \\
\hline \multicolumn{4}{|c|}{$\begin{array}{l}\text { 15. SUPPLEMENTARY NOTES } \\
\text { Prepared by Astrionics Laboratory, } \\
\text { Science and Engineering }\end{array}$} \\
\hline \multicolumn{4}{|c|}{$\begin{array}{l}\text { A control system containing two nonlinear elements may be analyzed in the parameter } \\
\text { plane to determine the existence, stability, and values of amplitude and frequency of limit cycles } \\
\text { By using describing functions to represent the nonlinearities, the system characteristic equation } \\
\text { may be obtained. Two adjustable parameters are selected, each containing one of the describing } \\
\text { functions and possibly several control system gains. A correlation between these parameters an } \\
\text { the roots of the characteristic equation is determined by mapping stability contours from the com } \\
\text { plex s-plane onto the chosen parameter plane. A relationship between the inputs to the two non- } \\
\text { linearities is determined next, and a locus representing the variation of the describing functions } \\
\text { also is plotted on the parameter plane. If this locus and the stability contour associated with a } \\
\text { pair of pure imaginary roots intersect, the existence and characteristics of a limit cycle are in- } \\
\text { dicated. Particular emphasis is placed on organizing the equations so that they may be readily } \\
\text { solved with a digital computer. }\end{array}$} \\
\hline \multicolumn{4}{|l|}{$\begin{array}{l}\text { Nonlinear stability theory } \\
\text { Sescribing functions } \\
\text { Attitude control }\end{array}$} \\
\hline $\begin{array}{l}\text { 19. SECURITY CLASSIF. (of this report) } \\
\text { Unclassified }\end{array}$ & $\begin{array}{l}\text { 20. SECURITY CLASSIF. (of this } \\
\text { Unclas sified }\end{array}$ & $\begin{array}{c}\text { 21. NO. OF PAGES } \\
17\end{array}$ & $\begin{array}{ll}\text { 22. } & \text { PRICE } \\
& \$ 3.00\end{array}$ \\
\hline
\end{tabular}




\section{TABLE OF CONTENTS}

Page

SUMMARY $\ldots \ldots \ldots \ldots \ldots \ldots \ldots \ldots \ldots \ldots \ldots \ldots \ldots$

INTRODUCTION $\ldots \ldots \ldots \ldots \ldots \ldots \ldots \ldots \ldots \ldots \ldots \ldots$

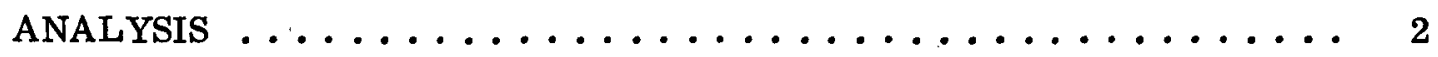

CONCLUSIONS $\ldots \ldots \ldots \ldots \ldots \ldots \ldots \ldots \ldots \ldots$

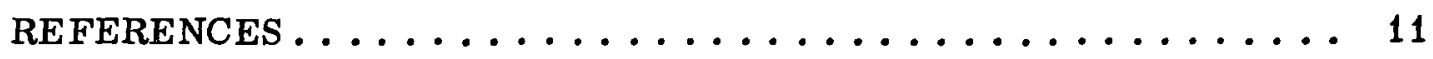

\section{LIST OF ILLUSTRATIONS}

Figure

Title

1. Control system containing two nonlinearities $\ldots \ldots \ldots \ldots 3$

2. Space vehicle attitude control model $\ldots \ldots \ldots \ldots \ldots \ldots$

3. $P_{0}-P_{1}$ parameter plane $\left(a_{0}=0.5, a_{1},=1, \tau=0.2\right.$, and

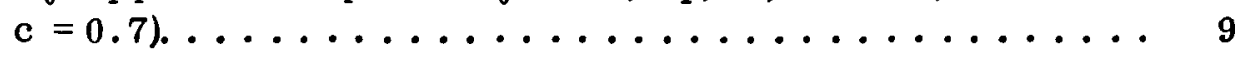

4. a. Computer simulation: $\theta(0)=0.4 \mathrm{deg}$ (time scale:

$2.5 \mathrm{~s} / \mathrm{div}) \ldots \ldots \ldots \ldots \ldots \ldots \ldots \ldots \ldots$

b. Computer simulation: $\theta(0)=0.1 \mathrm{deg}$ (time scale:

$2.5 \mathrm{~s} /$ div $) \ldots \ldots \ldots \ldots \ldots \ldots \ldots \ldots \ldots$

5. Computer simulation: forced solution (time scale:

$2.5 \mathrm{~s} /$ div $) \ldots \ldots \ldots \ldots \ldots \ldots \ldots \ldots \ldots \ldots$ 


\title{
ANALYSIS OF A CONTROL SYSTEM CONTAINING TWO NONLINEARITIES
}

\author{
SUMMARY
}

A control system containing two nonlinear elements may be analyzed in the parameter plane to determine the existence, stability, and values of amplitude and frequency of limit cycles. By using describing functions to represent the nonlinearities, the system characteristic equation may be obtained. Two adjustable parameters are selected, each containing one of the describing functions and possibly several control system gains. A correlation between these parameters and the roots of the characteristic equation is determined by mapping stability contours from the complex s-plane onto the chosen parameter plane. A relationship between the inputs to the two nonlinearities is determined next, and a locus representing the variation of the describing functions also is plotted on the parameter plane. If this locus and the stability contour associated with a pair of pure imaginary roots intersect, the existence and characteristics of a limit cycle are indicated. Particular emphasis is placed on organizing the equations so that they may be readily solved with a digital computer.

\section{INTRODUCTION}

A technique has been developed by Siljak [1] to analyze systems containing two nonlinear elements if they have a common input or if their inputs are related by a linear differential equation. Viswanadham and Deekshatulu [2] and Gelb and Vander Velde [3] present techniques for analyzing a system whose inputs to the nonlinear elements are related by a nonlinear differential equation. A technique similar to that developed by Siljak is presented here to enable one to analyze this latter system.

By using describing functions to represent the nonlinearities, the system characteristic equation may be obtained. Two àdjustable párāmeters are se= lected, each containing one of the describing functions and possibly several control system gains. A correlation between these parameters and the roots of the characteristic equation is determined by mapping stability contours from the complex $s$-plan onto the chosen parameter plane. 
A relationship between the inputs to the two nonlinearities is determined next, and a locus representing the variation of the describing functions also is plotted on the parameter plane. If this locus and the stability contour associated with a pair of pure imaginary roots intersect, the existence and characteristics of a limit cycle are indicated. From this point of intersection, the frequency and magnitude of the indicated limit cycle may be determined as a function of the characteristics of the nonlinearities and of the adjustable control system gains. The stability of the limit cycle is investigated by determining if all characteristic equation roots, other than the pair of pure imaginary roots, have negative real parts. This condition is indicated readily on the parameter plane. The behavior of the limit cycle when a small perturbation is applied to its amplitude also is apparent on the parameter plane.

To demonstrate the application of this technique, a typical attitude control system for a large space vehicle is analyzed. The results of the analysis are confirmed by analog simulation.

\section{ANALYSIS}

The system under consideration is portrayed in Figure 1 . It is assumed that the inputs $x_{1}$ and $x_{2}$ to the nonlinearities are sinusoidal and that the applicability conditions permitting the use of the describing functions $N_{1}\left(A_{1}, \omega\right)$ and $N_{2}\left(A_{2}, \omega\right)$ in lieu of the actual nonlinearities $n_{1}$ and $n_{2}$ are satisfied, where

and

$$
x_{1}=A_{1} \sin \omega t
$$

$$
\left.\mathrm{x}_{2}=\mathrm{A}_{2} \sin (\omega \mathrm{t}-\psi) .\right\}
$$

It also is assumed that only the first harmonic of the signal $x_{1}$ passes through the first nonlinearity $n_{1}$. Finally, it is assumed that the system parameters are time invariant.

The describing functions are used to linearize the system characteristic equations; i.e.

$$
i+N_{1} G_{1}(s) N_{2} G_{2}(s)=0,
$$

which leads to

$$
\Delta(s)=\sum_{k=0}^{n} f_{k} s^{k}=0 .
$$




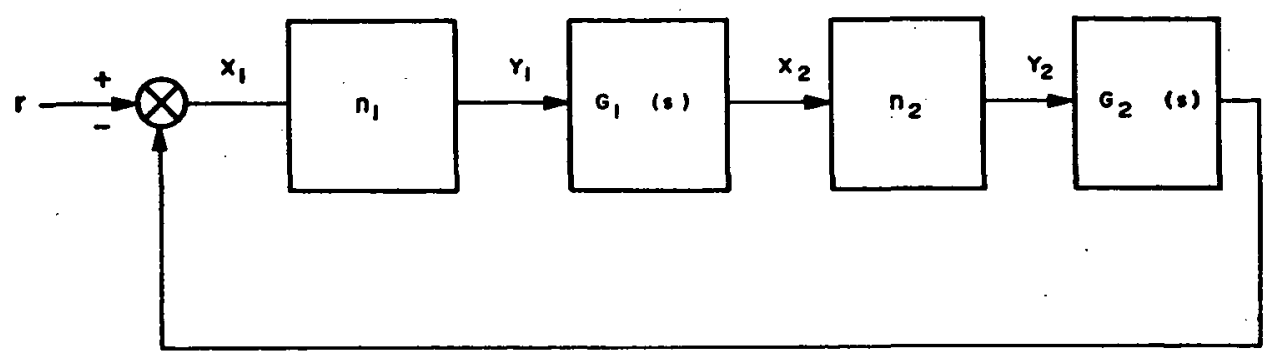

Figure 1. Control system containing two nonlinearities.

where

$$
f_{k}=b_{k} P_{1}+c_{k} P_{2}+d_{k}
$$

Parameters $P_{1}$ and $P_{2}$ are defined as

$$
P_{1} \equiv l_{1} N_{1} \text { and } P_{2} \equiv l_{1} N_{2} \text {, }
$$

where $b_{k}, c_{k}, d_{k}, l_{1}$, and $l_{2}$ are constants or system parameters of the linear portion of the system.

A correlation between parameters $P_{1}$ and $P_{2}$ and the roots of the characteristic equation is determined by mapping certain stability contours from the complex s-plane onto the $P_{1}-P_{2}$ parameter plane. The stability contour chosen for this portion of the analysis is the imaginary axis of the $s$-plane.

$$
\mathrm{s}=\mathrm{i} \Omega,
$$

which will be referred to as the $\zeta=0$ contour. To facilitate computation and to provide flexibility for use in later analysis, $s$ of equation (2) may be replaced by

$$
\mathrm{s}^{\mathrm{k}}=\mathrm{X}_{\mathrm{k}}+\mathrm{iY} \mathrm{Y}_{\mathrm{k}}
$$

where $X_{k}$ and $Y_{k}$ may be obtained by using the recurrence formulas [1]: 


$$
\left.\begin{array}{c}
\mathrm{X}_{\mathrm{k}+1}+2 \omega_{\mathrm{n}} \zeta \mathrm{X}_{\mathrm{k}}+\omega_{\mathrm{n}}^{2} \mathrm{X}_{\mathrm{k}-1}=0 \\
\mathrm{Y}_{\mathrm{k}+1}+2 \omega_{\mathrm{n}} \zeta \mathrm{Y}_{\mathrm{k}}+\omega_{\mathrm{n}}^{2} \mathrm{Y}_{\mathrm{k}-1}=0 .
\end{array}\right\}
$$

Equation (2) may be separated into its real and imaginary parts and regrouped:

$$
\operatorname{Re}\{\Delta(\mathrm{s})\}=\sum_{\mathrm{k}=0}^{\mathrm{n}} f_{\mathrm{k}} \mathrm{x}_{\mathrm{k}}=\mathrm{B}_{1} \mathrm{P}_{1}+\mathrm{C}_{1} \mathrm{P}_{2}+\mathrm{D}_{1}=0
$$

and

$$
\operatorname{Im}\{\Delta(\mathrm{s})\}=\sum_{\mathrm{k}=0}^{\mathrm{n}} f_{\mathrm{k}} \mathrm{Y}_{\mathrm{k}}=\mathrm{B}_{2} \mathrm{P}_{1}+\mathrm{C}_{2} \mathrm{P}_{2}+\mathrm{D}_{2}=0
$$

where

$$
\begin{aligned}
& \mathrm{B}_{1}=\sum_{\mathrm{k}=0}^{\mathrm{n}} \mathrm{b}_{\mathrm{k}} \mathrm{x}_{\mathrm{k}}, \quad \mathrm{c}_{1}=\sum_{\mathrm{k}=0}^{\mathrm{n}} \mathrm{c}_{\mathrm{k}} \mathrm{x}_{\mathrm{k}}, \quad \mathrm{D}_{1}=\sum_{\mathrm{k}=0}^{\mathrm{n}} \mathrm{d}_{\mathrm{k}} \mathrm{x}_{\mathrm{k}}, \\
& \mathrm{B}_{2}=\sum_{\mathrm{k}=0}^{\mathrm{n}} \mathrm{b}_{\mathrm{k}} \mathrm{Y}_{\mathrm{k}}, \quad \mathrm{C}_{2}=\sum_{\mathrm{k}=0}^{\mathrm{n}} \mathrm{c}_{\mathrm{k}} \mathrm{Y}_{\mathrm{k}}, \quad \text { and } \quad \mathrm{D}_{2}=\sum_{\mathrm{k}=0}^{\mathrm{n}} \mathrm{d}_{\mathrm{k}} \mathrm{Y}_{\mathrm{k}} \text {. }
\end{aligned}
$$

Equations (8.a) and (8.b) may be solved for $P_{1}$ and $P_{2}$ which may be plotted on the $P_{1}-P_{2}$ parameter plane as functions of frequency $\Omega$. This curve is the $\zeta=0$ stability contour associated with complex conjugate roots. The boundary separating stable real roots from unstable ones is determined by setting $\mathbf{s}=0$ in equation (2) and solving for $P_{2}$ as a function of $P_{1}$. The resulting curve also is plotted on the $P_{1}-P_{2}$ parameter plane. The stable region (corresponding to the left half of the s-plane) in the parameter plane is determined by observing the sign of the Jacobian (J) [1].

In determining regions of stability and instability on the parameter plane, one must be alert for the possible existence of singular cases where the Jacobian $J \equiv 0^{2}$. This may happen for certain combinations of $N_{1}$ and $N_{2}-a$ point not mentioned by Viswanadham and Deekshatulu [2]. (Analysis of the Jacobian associated with the example presented in Viswanadham's and Deekshatulu's paper [2] shows the existence of several singular points for certain combinations of values of $N_{1}, N_{2}$, and $\omega_{.}$) In such cases, the mapping of 
certain points from the complex s-plane onto the parameter plane may result in loci of points or in distinct points. Hence, additional stability boundaries may occur on the parameter plane. One such singular,case corresponds to the mapping of the origin of the s-plane onto the parameter plane as the real root stability boundary.

To obtain some insight into the choice of values for adjustable gains of the linear portion of the system, two such gains (or combinations of gains) may be chosen as parameters $\left(\alpha_{1}\right.$ and $\left.\alpha_{2}\right)$. Considering linear operation of the system, the characteristic equation (2) may be written in terms of $\alpha_{1}$ and $\alpha_{2}$ by setting $\mathrm{N}_{1}$ and $\mathrm{N}_{2}$ equal to unity; i.e.,

$$
f_{k}=b_{k} \quad \alpha_{1}+c_{k} \alpha_{2}+d_{k}
$$

Stability contours associated with chosen values of the damping ratio $\zeta$ may be plotted as functions of $\omega_{n}$ on the $\alpha_{1}-\alpha_{2}$ parameter plane by mapping the line

$$
s=-\zeta \omega_{n}+i \omega_{n} \sqrt{\left(1-\xi^{2}\right)}
$$

from the s-plane onto the $\alpha_{1}-\alpha_{2}$ parameter plane. Any roots lying on this line will possess an associated damping ratio specified by $\zeta$. If equation (9) is substituted for equation (3) and $P_{1}$ and $P_{2}$ are replaced by $\alpha_{1}$ and $\alpha_{2}$ in equations (8.a) and (8.b), they may be solved by $\alpha_{1}$ and $\alpha_{2}$ for various values of $\zeta$. Then, values of $\alpha_{1}$ and $\alpha_{2}$ may be chosen for desired values of $\zeta$ and $\omega_{n}$.

The relationship between $x_{1}$ and $x_{2}$ may be determined, assuming that $G_{1}(s)$ is a low-pass function and that only the first harmonic passes through $n_{1}$. Since $N_{1}\left(A_{1}, \omega\right)$ is known, $A_{2}$ may be calculated as a function of $A_{1}$ and $\omega$ :

$$
A_{2}=\left|G_{1}(i \omega)\right| N_{1}\left(A_{1}, \omega\right) A_{1}
$$

For chosen values of $A_{1}$ and $\omega, N_{2}$ may be found using equation (11). Thus, $N_{2}$ may be plotted versus $N_{1}$ as a function of $A_{1}$ and $\omega$. Using equation (4), one may plot this nonlinear locus on the $P_{1}-P_{2}$ parameter plane, as a function of $A_{1}$, for various values of $\omega$. If the locus intersects the $\zeta=0$ curve, a limit cycle is indicated if the frequencies of the locus $(\omega)$ and the $\zeta=0$ curve $(\Omega)$ match; this is the frequency of oscillation of the limit cycle. The amplitude of the limit cycle is determined from the value of $A_{1}$ corresponding to the intersection. For a limit cycle to be stable, it is necessary but not-sufficient-that-all-roots(other than the pair of complex roots lying on the imaginary axis of the s-plane) 
lie to the left of the imaginary axis. Hence, the intersection of the locus and the $\zeta=0$ curve must lie on a boundary of the stable region (the entire $\zeta=0$ curve is not necessarily a stability boundary-a point omitted by Siljak [1]). If the locus crosses from the unstable region as $A_{1}$ increases, a stable limit cycle is indicated (and vice versa if it crosses from the stable region into the unstable region). If no intersection occurs and the locus remains in the stable region for all values of $A_{1}$, linear stable operation is indicated. If the locus remains in the unstable region, unstable operation without a limit cycle is indicated.

Example. Consider a typical pitch-plane attitude control system for a space vehicle (Fig. 2). The rigid body dynamics are represented by the trans-: fer function

$$
\mathrm{G}_{\mathrm{RB}}(\mathrm{s}) \equiv \dot{\theta}(\mathrm{s}) / \beta_{\mathrm{L}}(\mathrm{s})=\mathrm{c} / \mathrm{s}
$$

where

$$
\mathrm{c}=\left(\partial \mathrm{L} / \partial \beta_{\mathrm{L}}\right) \beta_{\mathrm{L}} \mathrm{l}_{\mathrm{g}} / \mathrm{I}
$$

The distance between the center of mass and the point of application of the thrust is denoted by $1_{g}$, the lateral component of thrust by $L$, and the moment of inertia about the pitch axis by $\mathrm{I}$.

The system characteristic equation may be written in the form of equation (2):

$$
\Delta(s)=\tau_{s}^{3}+s^{2}+a_{1} c N_{s} N_{D} s+a_{0} c N_{s}=\sum_{k=0}^{3} f_{k} s^{k}=0,
$$

where $\mathrm{N}_{\mathrm{s}}$ and $\mathrm{N}_{\mathrm{D}}$ represent describing functions associated with the saturation characteristic and the dead-zone characteristic, respectively. Convenient parameters are

$$
\mathrm{P}_{0} \equiv \mathrm{a}_{0} \mathrm{~N}_{\mathrm{S}} \text { and } \mathrm{P}_{1} \equiv \mathrm{a}_{1} \mathrm{~N}_{\mathrm{S}} \mathrm{N}_{\mathrm{D}} \text {, }
$$

where

$$
f_{k}=b_{k} P_{0}+c \tilde{P}_{1}+d_{k}
$$




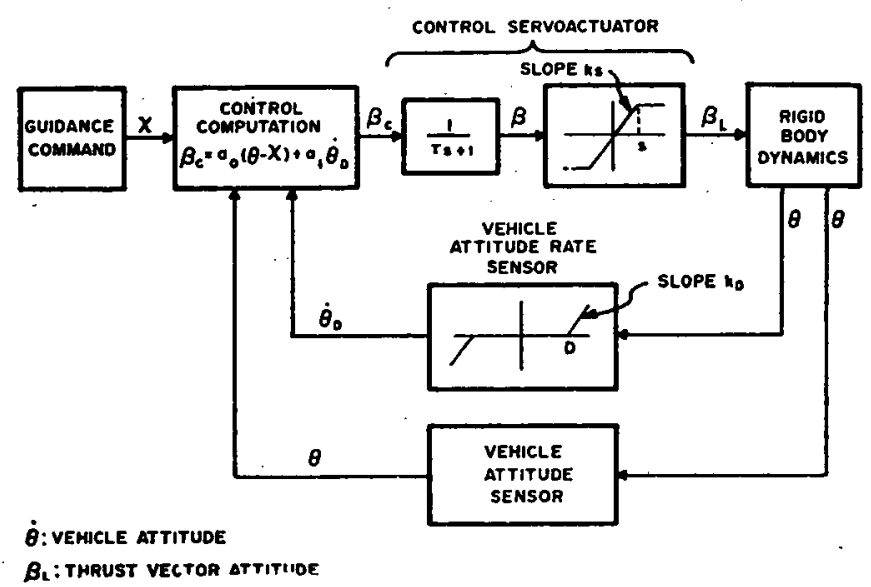

Figure 2. Space vehicle attitude control model.

In the manner indicated by equations (8.a) and (8.b), the $\zeta=0$ contour may be determined:

$$
P_{0}=\Omega^{2} / \mathrm{c}
$$

and

$$
P_{1}=\tau \Omega^{2} / \mathrm{c}=\tau P_{0}
$$

where

$$
\mathrm{J}=\mathrm{c}^{2} \Omega>0, \quad \forall \Omega>0 .
$$

In a design problem it is desirable to separate the describing functions $\mathrm{N}_{\mathrm{S}}$ and $N_{D}$ rather than have them appear as a product in the parameter $P_{1}$. This is achieved by defining $P_{1}$ :

$$
P_{1} \equiv a_{1} N_{D} / a_{0}
$$

Examination of the Jacobian reveals that it will become identically equal to zero only if $\omega$ equals-zero (since c is_non-zero). This corresponds to the singular case associated with the real root stability boundary which is

$$
P_{0}=0 .
$$


Now the stability boundaries may be plotted, using equations (16), (19), and (20) (Fig. 3). The number of stable roots of the characteristic equation is indicated within square brackets for each region.

To determine suitable values for the adjustable control gains, $a_{0}$ and $a_{1}$, linear operation is assumed and contours corresponding to various values of $\zeta$ may be plotted as functions of $\omega_{n}$. A typical contour (for $\zeta=0.5$ ) also is shown in Figure 3; values of $\omega_{n}$ and $\Omega$ are shown in parentheses. Numerical values must be assigned to the constants $\tau, a_{0}, a_{1}, k_{s}, k_{D}, S, D$, and $c$. Constants $\tau, \mathrm{k}_{\mathrm{D}}$, and $\mathrm{D}$ are fixed by the design of the actuator. Values representative of contemporary hardware are $\tau=0.2 \mathrm{~s}, \mathrm{k}_{\mathrm{S}}=1$, and $\mathrm{S}=1 \mathrm{deg}: \mathrm{A}$ typical rate gyroscope has values of $k_{D}=1$ and $D=0.1 \mathrm{deg} / \mathrm{s}$. Parameter $\mathrm{c}$ is a function of flight time and, for a typical launch vehicle, varies slowly between 0.5 and 2.5. The value of 0.7 is chosen from the example. Values of $a_{0}$ and $a_{1}$ are chosen from Figure 3 , assuming linear operation and $\zeta \approx 0.7$ and $\omega_{\mathrm{n}} \approx 0.6$ $\mathrm{rad} / \mathrm{s} ; a_{0}=0.5$ and $a_{1}=1$.

Assuming the following forms for $\mathrm{x}_{1}$ and $\mathrm{x}_{2}$ :

$$
\mathrm{x}_{1} \equiv \beta=\mathrm{A}_{\mathrm{s}} \sin \Omega \mathrm{t}
$$

and

$$
\mathrm{x}_{2} \equiv \dot{\theta}=\mathrm{A}_{\mathrm{D}} \sin \left(\Omega t+\psi_{1}\right)
$$

and utilizing the assumptions of the foregoing section, the relationship. between $A_{D}$ and $A_{s}$ is

$$
A_{D}=\mathrm{cN}_{\mathbf{s}}\left(A_{s}, \omega\right) A_{s} / \omega
$$

Describing function relationships for $\mathrm{N}_{s}\left(k_{s}, A_{s}, S\right)$ and $\mathrm{N}_{D}\left(k_{D}, A_{D}, D\right)$ are well known and readily available. From these relationships and equations (16), (17), (20), and (22), loci representing the variation of $N_{S}$ and $N_{D}$ may be plotted on the $P_{0}-P_{1}$ parameter plane as a function of $A_{s}$ for various values of $\omega$. These loci are shown as dashed lines in Figure 3. Sets of two figures within parentheses indicate corresponding values of $A_{S} / S$ and $A_{D} / D$. Since most loci shown rise vertically at $P_{0}=0.5$, the values shown for $A_{S} / S$ and $A_{D} / D$ correspond to the locus associated with $\omega=0.592$. It is seen that a limit cycle 


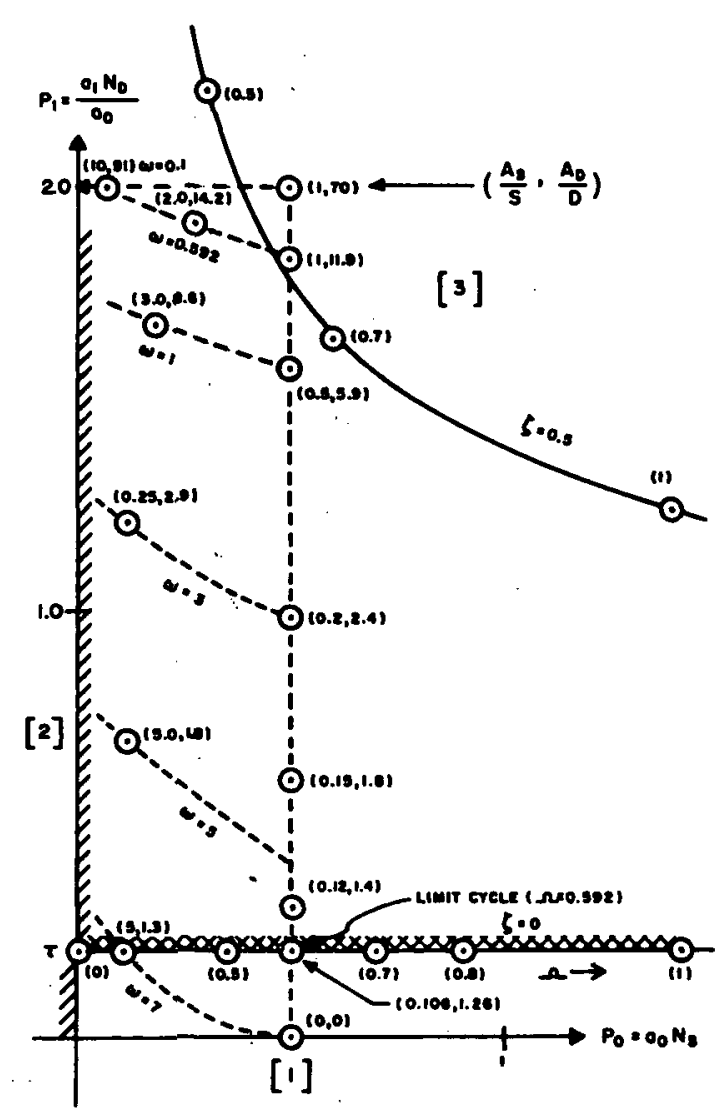

Figure 3. $P_{0}-P_{1}$ parameter plane $\left(a_{0}=0.5, a_{1}=1, \tau=0.2\right.$, and $c=0.7)$. cannot be avoided if otherwise nonlinear operation is to be precluded. It also is observed that only one limit cycle is possible, and it will be stable. The characteristics of the limit cycle for this example are read from the intersection of the $\zeta=0$ contour and the nonlinear locus as: $\Omega=0.592$; $P_{0}=0.5 ; P_{1}=0.2 ; A_{S}=0.106, S=1 ;$ and $A_{D}=0.126, D=0.1$. The predicted numerical results were confirmed by simulating the system on an analog computer, thereby increasing confidence in the technique and the assumptions. Figures 4 (a) and 4 (b) show these results for several initial conditions on $\theta$. Also of interest (although not analyzed) is the case where an input signal is applied. Simulation results, shown in Figure 5 , indicate that limit cycle operation will not occur when the system is forced by a ramp input, but as soon as the input levels off to a step input, sustained oscillations again occur.

In the actual design of a control system, the values chosen for $\tau, a_{0}$, $a_{1}, k_{S}, k_{D}, S$, and $D$ would be va ried (within constraints imposed by actual hardware implementation) to achieve other limit cycle characteristics so that the least undesirable characteristics could be obtained. Also, the problem would be analyzed for the entire range of values that $c$ assumes during predicted flight.

\section{CONCLUSIONS}

The parameter plane technique of stability analys is can be-applied to-a model of a system containing two nonlinearities whose inputs are related by a nonlinear differential equation. The constraints imposed on the system are prescribed, and limit cycle operation and characteristics may be predicted. In cases where limit cycle operation can be avoided, relative stability characteristics can be established by choosing the distribution of the roots of the characteristic equation through the variation of two adjustable parameters. 


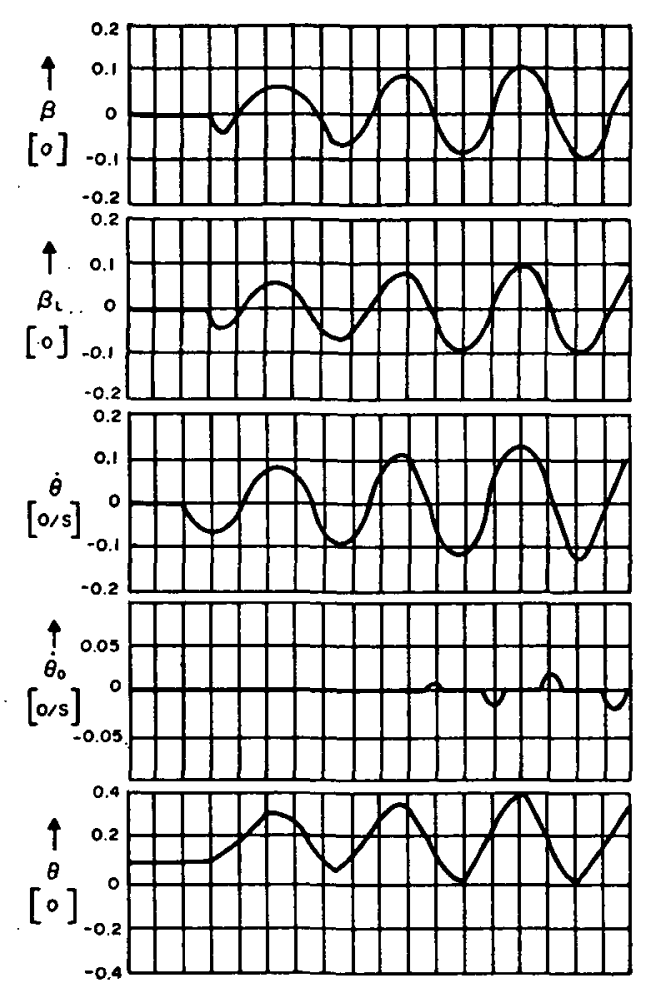

Figure 4(a). Computer simulation: $\theta(0)=0.4 \mathrm{deg}$ (time scale: 2.5 s/div).
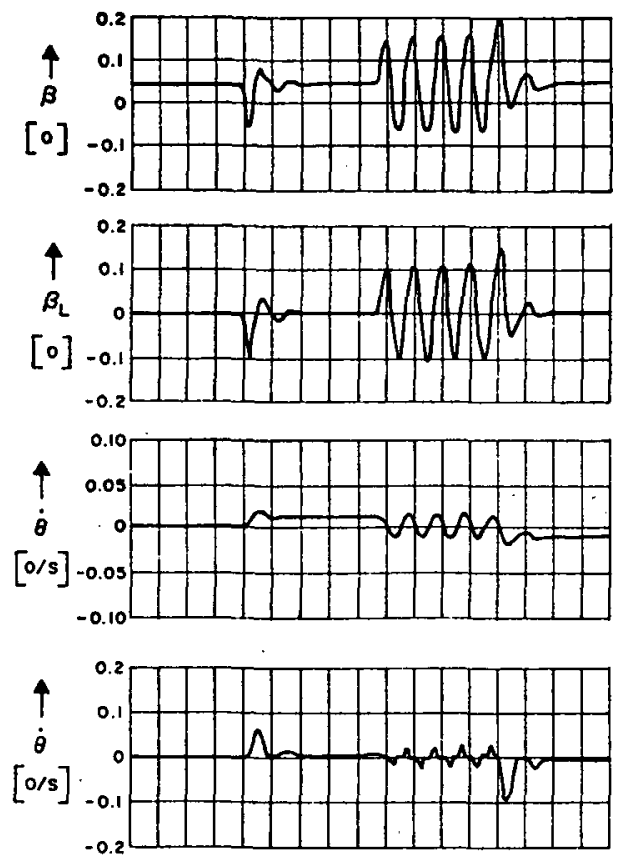

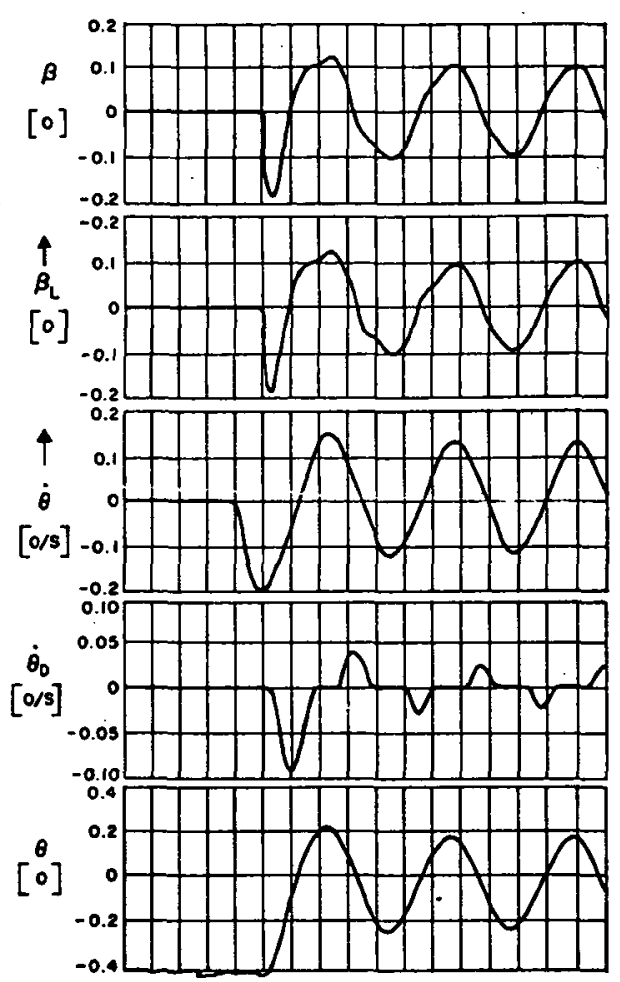

Figure $4(\mathrm{~b})$. Computer simulation: $\theta(0)=0.1 \mathrm{deg}$ (time scale: $\mathbf{2 . 5}$ s/div).
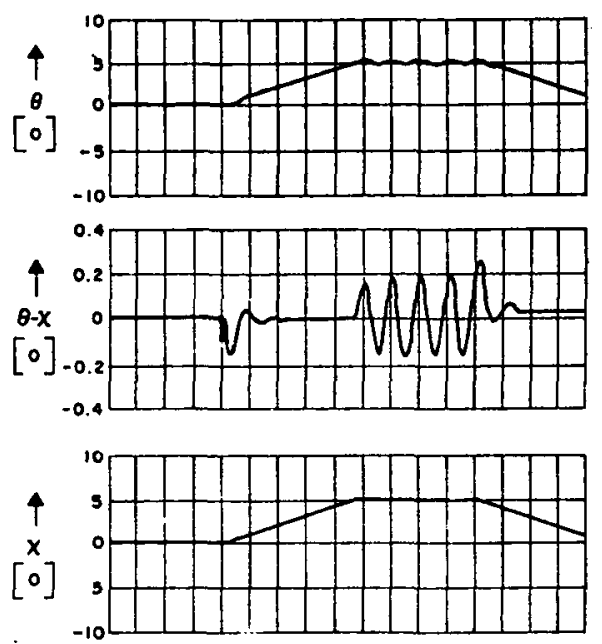

Figure 5. Computer simulation: forced solution (time scale: $2.5 \mathrm{~s} /$ div) . 


\section{REFERENCES}

1. Siljak, D. D.: Nonlinear Systems . John Wiley \& Sons, Inc., New York, N. Y., 1969 .

2. Viswanadham, $\mathrm{N}_{\text {.; }}$; and Deekshatulu, B. L.: Stability Analysis of NonLinear Multivariable Systems. Int. J. Control, vol. 5, 1966, p. 369.

3. Gelb, Arthur; and Vander Velde, Wallace E.: Multiple-Input Describing Functions and Nonlinear Systems Design. McGraw-Hill Book Company, Inc., New York, N. Y., 1968. 


\section{APPROVAL \\ ANALYSIS OF A CONTROL SYSTEM CONTAINING TWO NONLINEARITIES}

By S. M. Seltzer

The information in this report has been reviewed for security classification. Review of any information concerning Department of Defense or Atomic Energy Commission programs has been made by the MSFC Security Classification Officer. This report, in its entirety, has been determined to be unclassified.

This document has also been reviewed and approved for technical accuracy .

\section{Hand. Xosenthle}

HANS H. HOSENTHIEN

Chief, Research and Development Analysis Office

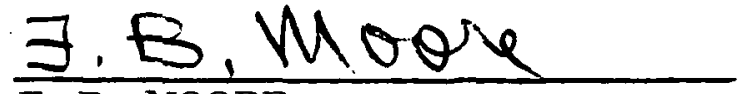

F. B. MOORE

Director, Astrionics Laboratory 